\title{
SAFETY II and other recent trends in SMS
}

\section{Libor Kurzweil ${ }^{1 *}$, Václav Řehoř}

\author{
${ }^{1}$ Praue Airport, Prague, Czech Republic \\ *Corresponding author: Prague Airport, Aviatická, 16108 Prague, Czech Republic, Email: kurzweil@ prg.aero
}

\begin{abstract}
The article deals with modern trends in safety management systems at airports. These include Safety II, Paperless SMS, transference of confidence and responsibility to operating employees, and creation of a system to ensure safety at the airport despite the potential for human error.
\end{abstract}

\section{Keywords}

Enhanced operational safety; operational risks; Safety Management System; SMS; Safety II; Paperless SMS; Prague Airport

\section{Introduction}

The area of aviation safety has been experiencing a rapid development. This is due to the evolution of the safety theory [1][2], but also the constant refinement and supplement of aviation safety standards based on newly gained knowledge and experience from operations, both at the global and regional levels. Recently, the Annex 19 to the Chicago Convention has been updated to the second edition [3]. The ICAO 9859 Safety Management Manual is also being updated to the fourth edition [4]. Changes related to the implementation of new regulations, in particular [5] and [6], are gradually being implemented in the European Union. All these changes move the Safety management systems to greater complexity and quantity of information that have to be processed. This needs to be reflected in every civil aviation organization, including Prague Airport.

Václav Havel Airport Prague handled 15,415,001 passengers in 2017, an increase of $17.9 \%$ over 2016. This confirms its status of one of the fastest growing Group 2 airports in Europe, a category pertaining to $10-25$ million passengers. Compared to the previous 5 years, the recent rise in passenger numbers at Václav Havel Airport Prague constitutes a double digit increase - the first time this has occurred in the history of the airport. Overall, European airports reported an increase of $8.7 \%$ for the year. The most successful month in 2017 was July, which saw 1,703,193 travellers pass through the premises. On average, Prague Airport handled 42,233 passengers every day.

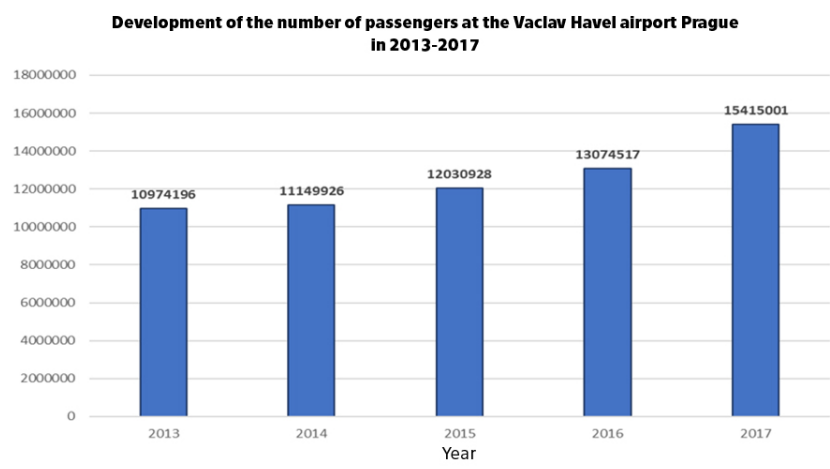

Figure 1. Evolution of passenger movement in the past 5 years

Another record-breaking number refers to movement at Václav Havel Airport Prague last year - 148,283 take-offs and landings in total. This upswing was due to new airlines 
operating out of Václav Havel Airport Prague, opening up new routes and increasing the capacity of existing ones [7]. In 2017, the network of air routes from the airport was extended to encompass 16 new destinations. Furthermore, 2 more routes were opened to additional airports in existing destinations (London City and London Southend). In general, it would seem that people are now willing to spend more on travel, in addition to which flights have become more affordable.

In 2017, a total 69 regular airlines operated out of Václav Havel Airport Prague, flying to 163 destinations. Most passengers travelled from Prague to elsewhere in Europe or to Africa; traffic to the latter rising by more than $66 \%$ annually, driven by tremendous interest in holidaying in the north of the continent. Most flights were destined for the United Kingdom (15 destinations, $+6.61 \%)$, followed by Italy $(+29.6 \%)$, Germany $(+8.1 \%)$, Russia $(+24.56 \%)$ and France $(+9.02 \%)$. London proved to be the biggest attraction, as usual; indeed, passengers can now fly to all six international London airports. The next most popular cities were Paris, Moscow, Amsterdam and Frankfurt.

\section{Safety II and Other Recent Trends}

\subsection{Safety II at Prague Airport}

Such dramatically increased operation of an airport, as described above, gives rise to safety hazards, hence close scrutiny has to be paid to any development in aviation safety. Notably, the immense growth in traffic in 2017 did not have any adverse impact in this respect. On the contrary, aviation safety indicators show better results over those of the previous year. LKPR has demonstrated a positive track record in this area. Nevertheless, room for improvement still exists, and steps are being taken by implementing the following:

1. traffic control at the crossing of TWY D/F and RWY $12 / 30$, with two existing and two new stop bars;

2. separation of RWY 12/30 from RWY 06/24 or introduction of a completely new RWY 06R/24L to eliminate the risk of RWY incursion;

3. Airport hydrant fuel distribution systems to reduce the risk of aircraft damage during handling operations.

In 2016-17, the decision was taken to enhance two of the highest monitored safety indicators: RWY incursion and damage to aircraft from handling operations. Under the auspices of the RWY and APRON safety teams, the Safety department developed prevention programmes so that Letiště Praha, a.s. and co-operating organisations could take measures to reduce the number of incidents, e.g. by conducting further training on local airport traffic rules. Indeed, said programmes have been introduced and both indicators show welcome annual improvements; the number of RWY incursion incidents has dropped from 10 to 8 , while only 6 incidents of minor aircraft damage were reported last year as compared to 13 in 2016.
The primary cause of all such incidents was human error The risk of this can be mitigated through properly selecting employees, analysing their motivations, and providing training and practical experience. However, the risk cannot be completely eliminated. The expectation is that RWY incursions and aircraft damage shall occur in 2018. Therefore, the purpose is to not devise a system free of human error but one that remains safe even if mistakes are made; sufficient safety barriers shall promptly reveal any instance of human error and prevent exacerbation of the situation. The system currently in place flagged up all such incidents in a timely fashion in 2017, except for two circumstances at the risky crossing of TWY D/F and RWY 12/30. To this end, a proposal was made in 2017 to enhance safety measures by adding two new STOP bars, which is a priority in 2018 .

A new certificate pursuant to Commission Regulation (EU) 139/2014, issued by the Civil Aviation Authority, confirms the high level of safety now in place.

\subsection{Key Safety Incidents and Thrie Causes}

The obvious priority of any airport safety department is to closely monitor all matters of concern, especially RWY incursions, and the employees at LKPR are no exception. We do our utmost to prevent any unauthorised entries into RWY, as they may result in accidents if other safety barriers also fail.

The causes of the worst aviation accidents in the history have rightly attracted great attention. Unfortunately, RWY incursion incidents are here to stay, although the acts (risks) of instigating the same change over time. Flawed technical equipment was a weakness that has since been overcome. Hence, the greatest risk at present is that such incidents are caused by the human factor. Most mistakes appear to be made by crews, even in relatively simple situations which used to be trouble free. The department at Prague Airport has been looking into circumstances like these. They may be due to an ever greater number of tasks that have to be performed when taxiing, the high data requirement for crews from all sides, attempts to make up for delays, and/or the growing complexity of airports. We look for causes at the very start of the career of a pilot. In the past, candidates for jobs in the civil aviation sector were people with experience, who had been members of flying clubs or in the military. Nowadays, it is commonplace that candidates take and pass a short (frozen) 0 -ATPL course. In fact, some incidents have occurred at the airport and elsewhere abroad that suggest this type of training is not sufficient to help pilots master all procedures.

The most frequent human error committed in RWY Safety is the failure to stop at a RWY holding point. Investigation usually reveals that crews have made this mistake, believing incorrectly that they had obtained permission. This represents a particularly dangerous trend, and preventing it is severely complicated for the infrastructure operator. Today, holding points are very clearly marked. However, it would seem that no matter how many signs - information or regulatory - are placed, or the sheer number of information campaigns con- 
ducted, the taxiing crew still believes that permission has been granted. The only effective infrastructure measure would be to introduce STOP bars use H24/7, which is not commonplace in Europe.

Nevertheless, the present advantage is that highly advanced, technological safety barriers are in place which supplement the skills of staff at the airport. Consequently, it is very likely that the current system will immediately detect a RWY incursion incident, permitting sufficient time to respond to the situation before it worsens and lives are endangered.

\subsection{Safety II}

The Safety Management System (SMS) has witnessed development to at least the same degree of rapidity as other areas of aviation. Although the wording stated in ICAO Annex 19 has not been altered to any great extent, advancements in new methodologies and concepts mark the way forward. The data collected by SMS, as implemented today, is the means by which this otherwise subjective area of study can be analysed, permitting description and presentation of the seriousness and probability of risks. In past decades, airport operators only gathered data on the most serious incidents, and information on paper was hard to process manually. Today, SMS amasses data on numerous safety-related incidents, controlled changes and the results of inspections and audits, as well as data seemingly unrelated to operational safety. Such data are stored in digital format, structured and easily accessible, hence processing them is straightforward. Giving rise to far more than mere statistics, the data is utilised for targeted performance management through smart safety indicators. We at the airport consider an indicator to be a statistical index of a certain safety risk - one which evolves over time, has a target value and can be potentially derived by SMS tools. Contrarily, it also possesses a critical value that should be avoided, which generates a red flag whenever a situation is gauged as approaching such a value. All such functions are a feature of specialised SMS software, i.e. programs providing an online overview of safety measures and warning when a critical value of a safety indicator is met.

Nevertheless, all of the above equates to nothing more than Safety I, a traditional approach to operational safety introduced at the very outset of aviation, the purpose of which is to attempt to identify causes of safety-related incidents. In other words, endeavour is made to discern the origins of an incident, why the net result is not as expected, the cause of technical failure, why employees did not comply with procedures, and so on.

Today, since aviation has become a very safe means of transport and the rate of safety-related incidents is very low compared to the number of operations (flights, handling, etc.), a completely new approach has emerged. In spite of the sheer volume of operations taking place on a daily basis, scant data actually relate to the safety-related incidents we experience. Whenever we at LKPR try to find out how and why something went wrong, usually only certain statistics are
Table 1. Principal differences between Safety I and Safety II according to source material [8]

\begin{tabular}{|c|c|c|}
\hline & Safety-I & Safety-II \\
\hline $\begin{array}{l}\text { Definition of } \\
\text { safety }\end{array}$ & $\begin{array}{l}\text { That as few thing as } \\
\text { possible go wrong. }\end{array}$ & $\begin{array}{l}\text { That as many things } \\
\text { as possible go right. }\end{array}$ \\
\hline $\begin{array}{l}\text { Safety man- } \\
\text { agement } \\
\text { principle }\end{array}$ & $\begin{array}{l}\text { Reactive, respond } \\
\text { when something hap- } \\
\text { pens or is categorised } \\
\text { as an unacceptable } \\
\text { risk. }\end{array}$ & $\begin{array}{l}\text { Proactive, contin- } \\
\text { uously trying to } \\
\text { anticipate develop- } \\
\text { ments and events. }\end{array}$ \\
\hline $\begin{array}{l}\text { View of the } \\
\text { human fac- } \\
\text { tor in safety } \\
\text { management }\end{array}$ & $\begin{array}{l}\text { Humans are predomi- } \\
\text { nantly seen as a liabil- } \\
\text { ity or hazard. }\end{array}$ & $\begin{array}{l}\text { Humans are seen as } \\
\text { a resource necessary } \\
\text { for system flexibility } \\
\text { and resilience. }\end{array}$ \\
\hline $\begin{array}{l}\text { Accident } \\
\text { investigation }\end{array}$ & $\begin{array}{l}\text { Accidents are caused } \\
\text { by failures and mal- } \\
\text { functions. The pur- } \\
\text { pose of an investiga- } \\
\text { tion is to indentify the } \\
\text { causes. }\end{array}$ & $\begin{array}{l}\text { Things basically hap- } \\
\text { pen in the same way, } \\
\text { regardless of the out- } \\
\text { come. The pur- } \\
\text { pose of an investi- } \\
\text { gation is to under- } \\
\text { stand how things usu- } \\
\text { ally go right as a } \\
\text { basis for explaining } \\
\text { how things occasion- } \\
\text { ally go wrong. }\end{array}$ \\
\hline $\begin{array}{l}\text { Risk assess- } \\
\text { ment }\end{array}$ & $\begin{array}{l}\text { Accidents are caused } \\
\text { by failures and mal- } \\
\text { functions. The pur- } \\
\text { pose of an investi- } \\
\text { gation is to identify } \\
\text { causes and contribu- } \\
\text { tory factors. }\end{array}$ & $\begin{array}{l}\text { To understand the } \\
\text { conditions where per- } \\
\text { formance variability } \\
\text { can become difficult } \\
\text { or impossible to mon- } \\
\text { itor and control. }\end{array}$ \\
\hline
\end{tabular}

available to us, which might paint an inaccurate picture of the given circumstance.

Therefore, we have adopted the Safety II approach to developments in aviation and operational safety.

Safety II offers an opposite approach to aviation safety. It seeks out and explores causes as to why the anticipated outcome is achieved in the absolute majority of cases, so in essence it explores what leads to correct consequences and reinforces proper workflow practices. Safety II attempts to describe the various reasons why things go to plan, and then finds ways to build on these to the greatest possible extent. It is obvious that such an optimistic approach acts as an incentive for further safety enhancements, but it is more exacting and precise than that. It generates a great deal of statistically relevant data, from which causes for positive outcomes can be detected.

In practice, Safety II is applied for inspecting aircraft handling processes. Every year, the SMS at Prague Airport is used to carry out hundreds of such inspections, each one involving assessment of more than 80 sub-procedures by Safety Inspectors. 


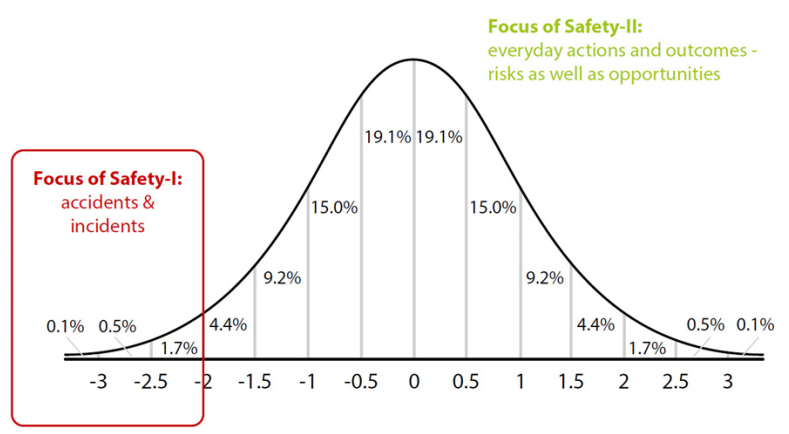

Figure 2. Focus of Safety I and Safety II according to source material [8]

Gathering data is simple, paperless and effective thanks to the SMS software. The online database acts as the repository of information entered by the Safety Inspector directly from the site of inspection, via a tablet connected to a Wi-Fi network. Any manual processing of the data is minimal, since it is only necessary to check the data and attach photographs and video recordings.

Staff at the airport also utilise a compliance system. This means we know exactly which handling procedures have been complied with properly and regularly by employees, a sign of being able to rely on them. As for other procedures where compliance is not $100 \%$, we check the relevant data to learn whether a mistake has been made or non-compliance has been encountered before. Afterwards, an investigation looks into the cause of any non-compliance, i.e. whether procedures have been wrongly implemented or circumvented for whatever reason.

From the description given above, it is apparent that the new inspection system is not solely a Safety II approach, but one that also applies Safety I in parallel. This shall remain the case for other applications, too. In fact, Safety II has not replaced Safety I but complemented it instead, hence both methods coexist and are linked together.

\subsection{Complexity and Flexibility}

The development of Safety II is, up to a point, informed by the growing complexity of aviation procedures. In fact, it is quite likely that the time will come when it is necessary to change the approach taken to operational safety. The days when all aircraft were handled identically have passed. Now each operator (i.e. client) typically has different requirements for handling in terms of scope, speed and procedure; indeed, it is not unusual for the demands of different operators to vary. Specifically, a procedure which is expressly requested by one operator could be strictly prohibited by another. An example of this is the standard procedure for placing a ground service equipment to an aircraft. Transport Rules and numerous operators request the presence of a driver and another person to provide assistance in the form of navigation, so the item is placed safely without damage being caused to the aircraft. However, other operators prohibit such a procedure.

The present state of affairs is that each aircraft is handled according to a unique set of procedures, depending on the operator, handling organisation, type of aircraft and aircraft stand. Rather than comprising uniform handling processes; it is a system made up of immense derogation and numerous exceptions. Endeavour has been made to capture all the various derogations, integrate them into procedures and train staff accordingly, but the quantity of documentation and variety of processes continues to multiply manyfold. There is a limit to the human capacity to remember complex procedures and exceptions. If this has not been exceeded yet, then it will be in the future unless the current approach is altered.

Any attempt to describe every single eventuality in a given procedure is essentially odd and overly bureaucratic. In contrast, following the path of flexibility and resilience is the way forward. Instead of creating complex written procedures, operators should encourage employees to be flexible and resilient, to handle the ever growing complexity on their own, get their bearings and make the right decision. In other words, there is a need to inspire confidence in and transfer responsibility to relevant employees. These aspects have been overlooked for the past 20 years, and it is the belief of the authors that they should be restored, at least to some extent. However, this hinges upon meeting one particular condition. Civil aviation has to attract qualified and responsible employees, people that are well-educated, correctly selected and properly trained; indeed, aviation should be at the core of their very being. There would also be a need to provide sufficient financial remuneration for such individuals. To this end, the ideal situation would be to attract a large number of applicants for posts in order to choose the best candidates from among them. This is certain to be extremely difficult for handling organisations that are already facing tough competition due to the enormous pressure brought to bear by aircraft operators to reduce costs.

Shortage of staff is rife and is being reported by all organisations.

\subsection{Paperless SMS}

The latest trend is a growing demand for incident and change documentation, inclusion of less significant events and modifications, and every little detail besides. This is apparent not only in aviation, but also in society as a whole, and there does not seem to be any sign of it coming to an end soon. For this reason, SMS has to face up to constraints in capacity. Basically, the human resources currently available are insufficient to fulfil all the requirements imposed by regulations and the national regulator. A possibility exists to expand the number of safety inspectors to a certain point. However, there is a lack of qualified experts in the labour market, so one way of resolving the situation would be to take on and train up young graduates, for instance, or retrain employees from other departments. Alternatively, beyond increasing the scale of human resources, further capacity could be facilitated by 
easing the workload of the existing inspectors, simplifying SMS procedures, limiting bureaucracy and clarifying the SMS process in general.

Overall, the number of safety-related incidents reported has risen in the long-term; email is the usual means of communication for these. With respect to each incident, the operator is required to perform the following tasks: confirm receipt of the given information; log the incident in the database; assess the severity of it; conduct an investigation; arrive at a decision on safety recommendations; and provide the incident reporter with the resultant data on how the incident was eventually resolved. Afterwards, it is necessary to monitor corrective measures and ensure that deadlines are met by responsible persons. Once again, this has to be entered into the database and assessed. As mentioned above, this process is normally done by email. Notably, such communications are not linked with the $\log$ in the database and are not tractable later, since the incident is resolved through multiple agents cooperating together.

Since 2015, the rate of change to infrastructure and procedure has risen dramatically (i.e. frequency of repairs, new structures, planned development, variety of aircraft, etc.). Therefore, it is necessary to assess in advance, via the change management process, whether any such alteration would be reasonably safe to implement. Presently, the regulator requests that the airport operator documents safety matters with relevant studies, even for changes where this was not customary in the past. The scope and complexity of the change management process has grown excessively, and this trend is set to continue once new EASA legislation is introduced.

In light of the growing number of entries, it is necessary to keep track of changes which have been assessed and in what manner, as well as of pending modifications and the status of investigations. If data for the SMS is communicated solely by email, it cannot be excluded that some information will be flagged as spam and blocked, or end up overlooked or hidden among other incoming correspondence. Hence, there is no guarantee that such data are referred for resolution in time or undergo assessment or investigation, or that emails on fulfilling safety recommendations are not lost.

The biggest weakness of the SMS at Prague Airport is that online information on safety is not accessible by any unit other than the Safety Department.

Applications that support the Safety Management System are currently under development, potentially eliminating paper documents and facilitating data flow. These would handle everything from the initial report and risk assessment, through to detailed investigation of safety recommendations and monitoring whether they are fulfilled. Furthermore, modules are available for the purpose of audits and inspection, providing the most elaborated statistical outputs and analytical options. Another benefit is that the Safety Department does not have to deal with any paperwork or process management or worry about searching for emails, allowing staff to focus on what is crucial - the data on operational safety. Potential solutions such as these are under consideration at present.

A possible improvement is that information from the Safety Department would be distributed to operating staff, strengthening links with safety. In essence, the board would have a "live" picture of safety matters, current "risks" of the operation, up-to-date reports on incidents, their severity and the status of any investigation, a "heat" map of the riskiest points, any completed studies and audits. Operating staff would also obtain similar information, and a clear online overview of live safety recommendations and their state of implementation.

Additionally, incident reporters would gain the opportunity to send safety reports, including anonymous ones. They would also be able to click a link and find out how a report has been handled, whether it is being resolved and the current outcome. Clear links between incidents and changes with safety recommendations and their implementation could exist. Moreover, responsible persons and SMS employees would automatically be advised of upcoming deadlines of corrective measures. Furthermore, investigating the causes of an incident would take less time due to the resultant reduction in paperwork for reporting data on incidents.

With the aid of software, the SMS can continue to function in an orderly fashion despite the growth in entries and extra demand for increased human resources. It will also be transparent and interactive, supporting a Safety (Just) culture establishing a stronger link between the Safety Department and operating staff, incident reporters and the Board of Directors. The reporting process for safety staff will be improved, as will awareness of the overall safety-related situation at Prague Airport, with the possibility of heightened, efficient response to safety risks.

\section{Conclusion}

Long-term, targeted regulation under the leadership of ICAO has made it possible for global aviation to achieve a high level of operational safety. For instance, this is proven by statistical data from 2017, reporting nil jet aircraft crashes for the period, which is an outstanding result. The situation today is that all the operational safety requirements of ICAO have been met satisfactorily. The staff at Prague Airport have exceeded aviation regulations to devise new methodologies, concepts and technologies to make the SMS even more precise and effective, as well as to facilitate sufficient capacity to handle the growing requirements of regulations and the regulator and for anticipated growth in air traffic in Europe.

\section{References}

[1] N Leveson. Engineering a Safer World: Systems Thinking Applied to Safety. The MIT Press, Cambridge, Mass, 2012.

[2] E Hollnagel. Safety-II in Practice: Developing the Resilience Potentials. Taylor \& Francis, 2017. 
[3] ICAO. Annex 19 to the Convention on International Civil Aviation: Safety Management. International Civil aviation Organization, 2016.

[4] N. A Abdel Hady. Overview on draft 4th edition of safety management manual - smm doc 9859 (summary of changes). presentation on nclb - aerodrome certification workshop/training. 2017.

[5] Regulation (eu) no 376/2014 of the european parliament and of the council on the reporting, analysis and followup of occurrences in civil aviation, amending regulation (eu) no 996/2010 of the european parliament and of the council and repealing directive 2003/42/ec of the european parliament and of the council and commission regulations (ec) no 1321/2007 and (ec) no 1330/ 2007., 2014.

[6] Commission implementing regulation (eu) 2015/1018 laying down a list classifying occurrences in civil aviation to be mandatorily reported according to regulation (eu) no $376 / 2014$ of the european parliament and of the council, 2015.

[7] Prague Airport. Prague airport web page, 2018. URL http://prg.aero.

[8] European Organisation for the Safety of Air Navigation. From safety-i to safety-ii: A white paper. 2013. 